[RADIOCARBON, VOL 28, No. 2A, 1986, P 215-222]

\title{
ACCELERATOR RADIOCARBON DATING AT SFU
}

\author{
D E NELSON, J S VOGEL, J R SOUTHON, and T A BROWN \\ Archaeology Department, Simon Fraser University, Burnaby, \\ BC V5A1S6, Canada
}

ABSTRACT. The Simon Fraser University accelerator mass spectrometry (AMS) facility has now been in semi-routine use since the beginning of 1985. The advantages and limitations for ${ }^{14} \mathrm{C}$ dating are described.

\section{INTRODUCTION}

In 1977, we began our attempts to make part-time use of a Tandem accelerator for ${ }^{14} \mathrm{C}$ dating (Nelson, Korteling \& Scott, 1977). This work has proceeded slowly, as the nearest Canadian accelerator was the FN at McMaster University, and as it was necessary to finance the project for the first few years by measuring ${ }^{10} \mathrm{Be}$ concentrations in several hundred oceanographic samples. Recently, we have had the opportunity to concentrate once again on our original goal of small-sample ${ }^{14} \mathrm{C}$ dating. Last year, at the Zurich AMS Conference (Nelson et al, 1984; Vogel et al, 1984), we described the equipment and methods that we were developing for this purpose, and reported our first attempts at measurements. Since then, we have completed the construction of the equipment. While more testing and familiarization remains to be done, we now have a semi-routine measurement capability, and have very usefully applied it to a variety of projects. In this paper, we describe the advantages and the limitations of our present facility.

\section{EQUIPMENT}

\section{Sample Preparation and Conversion to Graphite}

Sample preparation begins with the isolation of the carbon-containing material to be analyzed. For standard samples, we use the traditional ${ }^{14} \mathrm{C}$ purification methods, such as acid and base washes for routine wood and charcoal, cellulose extraction if there are complications with the wood, and collagen extraction for all bone samples. For some of the recent work, we have begun to develop more esoteric methods of isolating specific organic molecules. All samples are converted to $\mathrm{CO}_{2}$. Organic materials are combusted in a closed quartz tube containing $\mathrm{CuO}$, while carbonates are converted by reacting with acid.

The $\mathrm{CO}_{2}$ is catalytically reduced to a graphite coating on an iron powder using an improved version of the method previously described (Vogel $e t$ $a l, 1984)$. The new equipment is smaller, and the complete system with four separate reactors occupies $2.5 \mathrm{~m}$ on a bench top. We believe that $\mathrm{Fe}$ is the preferred catalyst, and have found that the reaction rate is highly dependent on its form.

At present, each sample requires 4-6 hours to convert, although we have shown that it is possible to do so in one-half hour. Unfortunately, the rapid conversion does not yield graphite of the best quality, and we prefer the slower process. Samples containing from 50 to $3000 \mu \mathrm{g}$ of carbon are 
conveniently handled with this equipment. The graphitization process isotopically fractionates the sample by no more than $1 \pm 0.5 \% 0$.

With the four reactors, it is possible to process eight samples in a working day. This throughput could easily be increased by attaching additional reactors, each of which consists of a valve, two quartz tubes, and a pressure gauge. While there are improvements that can yet be expected for this graphitization method, it is entirely adequate for our present measurement purposes, and is in routine use. Ca 1000 samples have been processed, mostly for testing purposes. We will give a more detailed description of the equipment and method elsewhere (Vogel et al, ms in preparation).

\section{The Ion Source and Injector}

For routine ${ }^{14} \mathrm{C}$ determinations on large samples, ca $300 \mu \mathrm{g}$ of the prepared graphite is pressed into a $1.1 \mathrm{~mm}$ diameter hole in an Al button. Twenty such samples, including unknowns, standards, and background samples are placed in a wheel in the ion source, which is a home-built version of the University of Washington reflected-beam cesium source (Schmidt \& Farwell, 1979). The negative carbon beam currents obtainable range as high as $60 \mu \mathrm{A}$, but are more commonly 20-40 $\mu \mathrm{A}$. Changing from one sample to another is done semi-automatically in ca 20 seconds. The sample wheel itself takes 2-3 hours to replace, as the Cs ionizer must be cooled and reheated. Since we run for several days on a 24-hour schedule, there is a certain resistance to decrease this turn-around time, as it provides a convenient rest period.

The negative ions from the source are injected into the accelerator by a device unlike any other injection system used in AMS. We simultaneously inject the ${ }^{13} \mathrm{C}$ and the ${ }^{14} \mathrm{C}$ beam into the accelerator, and thus obtain simultaneous measures of the ${ }^{13} \mathrm{C}$ and ${ }^{14} \mathrm{C}$ intensities. No attempt has yet been made to inject the ${ }^{12} \mathrm{C}$ beam as well, since it would seriously load the accelerator at these intensities. While there is provision in the design of the injector (Lobb et al, 1981) to reduce the intensity of the ${ }^{12} \mathrm{C}$ beam without altering those of the other isotopes, we have not done so, as the present mode of operation is satisfactory. Testing and evaluation of this device continues, and the operating characteristics are to be described in detail elsewhere (Southon et al, ms in preparation).

\section{Acceleration and Detection}

The McMaster FN accelerator has had no further modification since we last described it (Nelson et al, 1984). It is charged by a pelletron chain system and has spiral inclined field acceleration tubes installed. It is capable of operation to $10.5 \mathrm{MV}$, but we use it at only $7 \mathrm{MV}$ for ${ }^{14} \mathrm{C}$ dating.

The transmission through the accelerator (an important parameter to optimize) has been $>95 \%$, but last year it dropped to $\approx 80 \%$. A recent check showed that the stripper canal was correctly aligned. However, the accelerator column resistors have deteriorated with time, and the variations in resistance may be sufficient to misalign the beam entering the canal. Work on this problem is proceeding, as our experience indicates that good per- 
formance is very critically dependent on exact alignment of the accelerator components.

The accelerated ions are first separated in the usual laboratory $90^{\circ}$ analyzing magnet, and the stable isotope is detected with a position-sensitive Faraday cup, which also regulates the accelerator. The ${ }^{14} \mathrm{C}$ ions are directed into our dedicated analysis line by a $20^{\circ}$ switching magnet, and further filtered using a Wien filter. Detection is by a combination of gas-ionization and solid-state counters, and data analysis is done on-line with the laboratory VAX computer. The high-energy analysis line is now very stable and rarely gives trouble. In our dual-beam mode of operation, all the elements are set at the beginning of the run and remain unchanged until the end.

\section{PERFORMANCE FOR ${ }^{14} \mathrm{C}$ MEASUREMENTS}

Our standard operating procedure is to determine the ${ }^{14} \mathrm{C} /{ }^{13} \mathrm{C}$ ratio of the graphite prepared from an unknown and to follow it immediately with an identical measure of the NBS oxalic acid standard. A minimum of three such measurements are made on each unknown to provide an indication of the precision. The known-age secondary standards included in each wheel give a routine test of procedures.

The ${ }^{14} \mathrm{C}$ count rate for the modern standard is typically $30-60$ per second, depending on the ion source output for each sample. On an unusual occasion, it has been as high as $\approx 100$ per second. The typical time to accumulate 10,000 counts for the standard is ca 3-5 minutes, and measurements of large unknowns (ie, 200-300 $\mathrm{g}$ of graphite) normally require a total time of 10-15 minutes for samples of age $<10,000$ years, and about an hour for 40,000-year samples.

For small samples $(<150 \mu \mathrm{g}$ of graphite) the time required is greater because of the less intense beam currents available from the source. As an example, Figure 1 shows the analyzed ${ }^{13} \mathrm{C}$ beam current and the ${ }^{14} \mathrm{C} /{ }^{13} \mathrm{C}$ ratio for a sample that contained only $50 \mu \mathrm{g}$ of carbon; these are plotted as a function of analysis time. The ${ }^{12} \mathrm{C}$ beam from the source varied from ca $12 \mu \mathrm{A}$ at the beginning to ca $1 \mu \mathrm{A}$ at the end of the analysis period.

The age of the sample was found to be ca 3000 years. As can be seen in the plot, $10,000{ }^{14} \mathrm{C}$ atoms were detected in 15 minutes, and in total, $\approx 1 \%$ of the ${ }^{14} \mathrm{C}$ atoms in the original $\mathrm{CO}_{2}$ were actually counted. This overall detection efficiency of $\approx 1 \%$ has been confirmed on other samples.

There was speculation in the past that both the use of an old Nuclear Physics accelerator and our method of simultaneous injection would result in unacceptably high background rates. The first problem would be due to residual ${ }^{14} \mathrm{C}$ in the accelerator; the second would result from interferences by ions scattered from the intense stable beam that accompanies the ${ }^{14} \mathrm{C}$ through the accelerator. Both fears were unjustified. The background rates we (and others) find with the older machines are as low, if not lower, than those obtained with the purpose-built accelerators. We have put an upper limit on the contribution to our background from scattered stable isotopes; it is less than that expected from a 65,000-year-old sample, and therefore negligible compared to the other sources. 

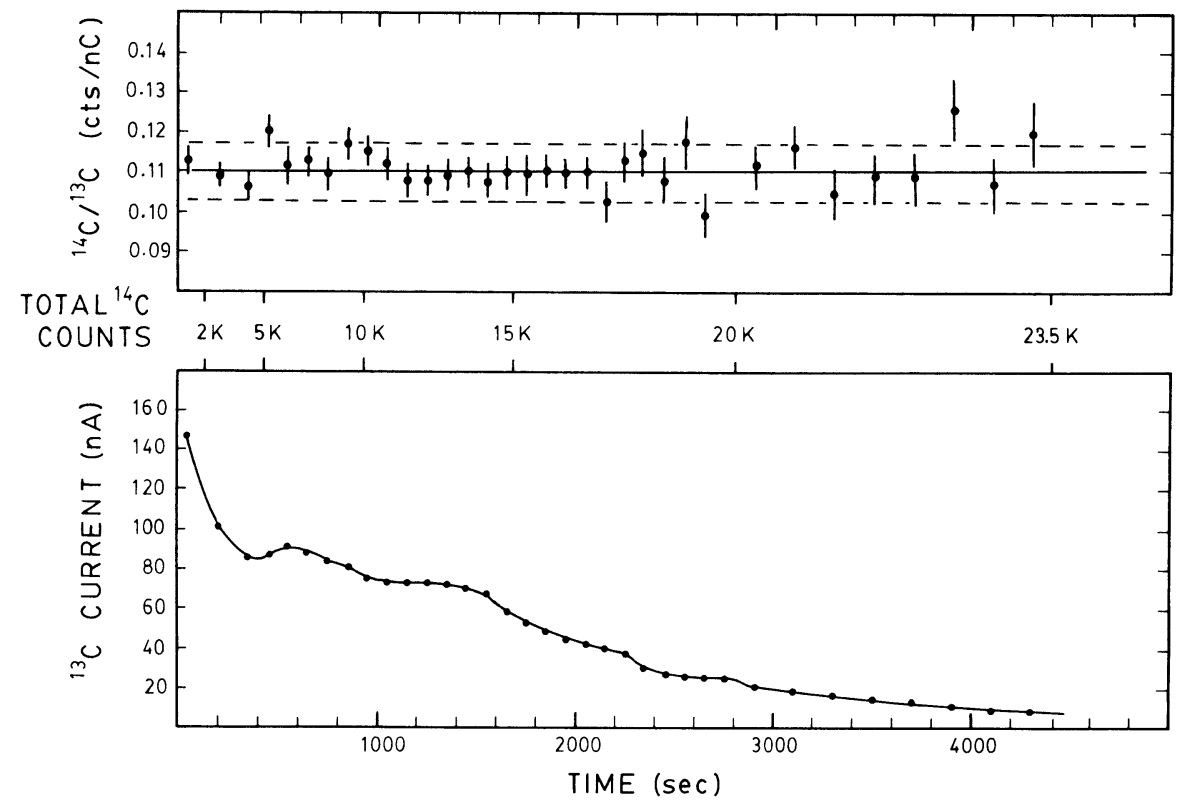

Fig 1. The ion-source ${ }^{13} \mathrm{C}^{-}$current and the measured ${ }^{14} \mathrm{C} /{ }^{13} \mathrm{C}$ ratio for a $50 \mu \mathrm{g}$ sample of graphite plotted as a function of analysis time.

Our background rates, as measured on burned and converted anthracite, are typically $0.2 \%$ modern for samples containing $>300 \mu \mathrm{g}$ of carbon, but increase to ca $2 \%$ modern for $50 \mu \mathrm{g}$ carbon samples. The equivalent ages are in the range 40-50,000 years for the larger samples, and ca 30,000 years for the small $50 \mu \mathrm{g}$ samples. In Figure 2, we plot the measured backgrounds as a function of the quantity of carbon, as well as the results for repetitive conversions and measurements on large, $1 \mathrm{mg}$ anthracite samples.

The results for the smaller samples suggest that an approximately constant amount of modern carbon is contaminating the samples. We believe this contamination occurs during burning or graphitization, as small portions of graphite taken from a larger sample give the same results as the larger samples.

The backgrounds for the larger samples are low, as shown in Figure $2 \mathrm{~B}$, and for most of our measurements of unknowns they are almost negligible. However, for very old samples the background variation is larger than we would wish. We can likely stabilize and perhaps further decrease the background, as at least a part is due to residual gases in the preparation system.

Within a run period, the observed measurement precision for the ${ }^{14} \mathrm{C} /$ ${ }^{13} \mathrm{C}$ isotopic ratio varies from ca $1 \%$ to $3-4 \%$ (at one standard deviation), depending on the age of the sample and the state of the equipment. We do not yet fully understand why the machine provides much better results during some run periods than others. 


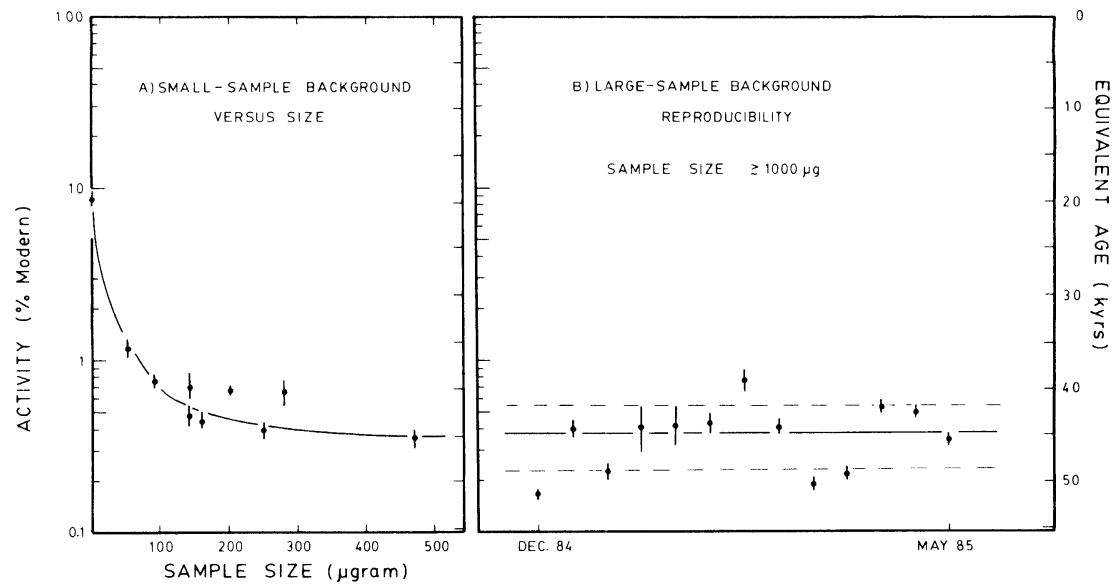

Fig 2. A) The backgrounds for graphite prepared from anthracite samples ranging from 0 to $500 \mu \mathrm{g}$. B) The background reproducibility for large anthracite samples of ca $1 \mathrm{mg}$.

However, it is clear that the ion source plays a major role. We have had recent difficulties due to a loss of focus on the Cs beam on the graphite sample. Previously, the Cs beam was focused well within the $1.1 \mathrm{~mm}$ diameter of the sample; presently, the beam spot size is $1-1.2 \mathrm{~mm}$ in diameter. The ion source emittance is thus increased, limiting "flat-topped" transmission. This has been a most irritating experience, as there have been no changes made to the source, and we have not been able to identify the cause of this new effect. Consequently, our most recent measurements have not been as precise as earlier ones.

Information on the longer-term reproducibility of the system is given in Figure 3. The $\mathrm{D}^{14} \mathrm{C}$ value for a sample of wood of age about two half-lives has been determined on different graphite preparations for each run since

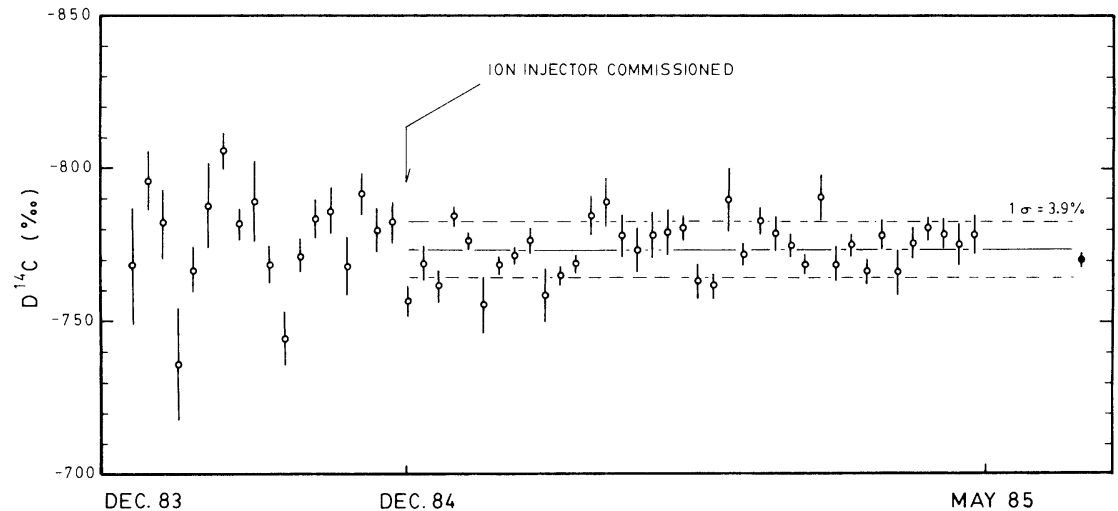

Fig 3. Repetitive determinations of a known-age sample of wood. The point at the extreme right is the average of four measurements by different $\beta$-counting laboratories. 
we started. This is the information that is truly of interest, as it gives an indication of the uncertainty in any individual measurement. The earlier values that show large scatter are those taken before the use of the injector. For the later determinations, the observed between-run variation for the ${ }^{14} \mathrm{C} /{ }^{13} \mathrm{C}$ ratio is ca $4 \%$ (at $1 \mathrm{SD}$ ), which is greater than the within-run precision of $1-2 \%$. There is obviously variation that is greater than that due to counting statistics alone. However, since this variation is apparently random, it should be possible to average the individual results to provide a more precise determination.

These data also provide information on the accuracy of the measurement, a topic that often receives too little attention in ${ }^{14} \mathrm{C}$ dating. The weighted-average age and uncertainty calculated from the data in Figure 3 is $11,930 \pm 25$, which is older by 100 years than the average of $11,830 \pm 60$ obtained from measurements reported by four different $\beta$-counting laboratories. The calculated uncertainty on our average determination is thus too small, and these data suggest that a minimum of $\mathrm{ca} \pm 80-100$ years is more appropriate.

We have also frequently analyzed wood samples of age ca 25,000 and 43,000 years. The data set is not so large as that above, but the results are consistent with the expected ages. However, none of these determinations were blind comparisons, and therefore they are not an entirely valid test of accuracy for a single unknown sample.

Soon after commissioning the injector, we attempted single, blind determinations on two samples of wood cellulose provided by M Stuiver and $\mathrm{P}$ Grootes. A subsequent comparison of results indicated that our measured age for the sample of age $<5000$ years differed from the Seattle highaccuracy value by ca 30 years, well within our estimated uncertainty of 95 years.

However, our result for the second sample, of age a little less than three half-lives, differed from the Seattle determination by almost 400 years. This difference is much larger than our estimated uncertainty of $\approx 100$ years. Subsequent determinations (no longer blind) have not resolved this discrepancy, as our values are consistently ca 250 years younger than the Seattle value. This is puzzling, especially since the results given in Figure 3 for wood of similar age are much closer to, and a bit older than the expected value. This will require detailed study. For the moment, though, we are satisfied with the accuracy of this new system, as it meets our present needs and will certainly improve as we gain experience.

The equipment has already been very useful in solving a number of problems that could not be attacked with the traditional ${ }^{14} \mathrm{C}$ method. Over the past several months, we have measured ca 160 unknown samples, and this number is growing rapidly. A few of these were for oceanography and the earth sciences, but the majority have been to solve problems in archaeology.

\section{CONCLUSIONS}

In summary, we now have semi-routine ${ }^{14} \mathrm{C}$ capability for samples containing carbon in amounts ranging from $\approx 50 \mu \mathrm{g}$ to 2 or $3 \mathrm{mg}$. We can reach 
ages of ca 45,000 to 50,000 years, and can obtain measurement accuracies of between 1 and $5 \%$ depending on the sample and the state of the equipment. For the most part, we also believe we can estimate the uncertainties for a particular measurement reasonably well.

When the equipment is tuned and running, ca 20 Holocene samples can be measured per 24-hour day, but our actual through-put is much less because of the limited amount of useful time we can obtain on the shared accelerator. Too much valuable time is devoted to setting up the equipment.

With the exception of the through-put, these capabilities match our present measurement requirements well. For the moment, all the users of the facility are much more interested in determinations on many small samples than they are in obtaining high measurement accuracy. However, that is a situation that is not likely to continue, and more work must be done to increase the accuracy that may be obtained reliably.

From our experience in developing and using this facility, we can make reasonable predictions for future development. The measurement accuracy now obtainable is approximately equal to that of the routine $\beta$-counting laboratories, and it is clear that much higher accuracy will eventually be reached. We can see that, even with our present design for the graphitization apparatus, it would be possible to process ca 20 samples of $\mathrm{CO}_{2}$ into graphite each technician-day. At present ion-source currents, these 20 samples could also be measured on the accelerator each day, unless they were old or high accuracy was required.

The work on small samples indicates that the limit has not yet been reached. Examination of Figure 1 enables one to make guesses on the sizes of sample that should be measurable for given age and accuracy requirements. We believe that it will be possible to usefully measure samples as small as $5-10 \mu \mathrm{g}$ of carbon. We have measured $20 \mu \mathrm{g}$ samples, but we do not yet have faith in the results.

This capability for measuring large numbers of small samples holds an enormous promise to all users of the ${ }^{14} \mathrm{C}$ method. The old maxim that "one date is no date" can properly be upheld when it is possible to obtain 20 or 30 dates on an archaeologic site or on a lake core. Since the size requirements are no longer restrictive, these dates can be made on carefully chosen samples that truly represent the event of interest.

These great advantages suggest to us that the AMS method will eventually replace $\beta$-counting. The only unknown is the time period for doing so. That will be determined solely by the problem of obtaining the funding to establish these expensive laboratories.

\section{ACKNOWLEDGMENTS}

We thank R Korteling for past assistance in designing and constructing this facility, $\mathrm{H}$ Roman for help with measurements, and the staff at the McMaster University Tandem Accelerator Laboratory for the use of their excellent machine. Funding is provided by NSERC of Canada, and by Simon Fraser and McMaster Universities. 


\section{REFERENCES}

Lobb, D E, Southon, J R, Nelson, D E, Wiesehahn, W and Korteling, R G, 1981, An ion injection system for use in Tandem Accelerator radioisotope dating devices: Nuclear Instruments \& Methods, v 179, p 171-180.

Nelson, D E, Korteling, R G and Stott, W R, 1977, Carbon-14: Direct detection at natural concentrations: Science, v 198, p 507.

Nelson, D E, Southon, J R, Vogel, J S, Korteling, R G and Ku, T L, 1984, Progress in radioisotope dating; The SFU Group, in Wolfli, W, Polach, $\mathrm{H} \mathrm{A}$ and Andersen, $\mathrm{H} \mathrm{H}$, eds, Interntl conf on AMS, 3rd, Proc: Nuclear Instruments \& Methods, v B5, p 139-143.

Schmidt, F H and Farwell, G W, 1979, An effective reflection-type geometry for sputter ion sources: Am Phys Soc Bull, v 24, p 650.

Vogel, J S, Southon, J R, Nelson, D E and Brown, T A, 1984, Performance of catalytically condensed carbon for use in accelerator mass spectrometry, in Wolfli, W, Polach, H A and Andersen, H H, eds, Interntl conf on AMS, 3rd, Proc: Nuclear Instruments \& Methods, v B5, p 289. 